\title{
Isoproterenol Potentiates Synaptic Transmission Primarily by Enhancing Presynaptic Calcium Influx via P- and/or Q-Type Calcium Channels in the Rat Amygdala
}

\author{
Chiung-Chun Huang, Kuei-Sen Hsu, and Po-Wu Gean \\ Department of Pharmacology, College of Medicine, National Cheng-Kung University, Tainan City, Taiwan
}

The effects of selective $\beta$-adrenergic receptor agonist isoproterenol (Iso) on neuronal excitability and synaptic transmission were investigated in brain slices of rat amygdala. Iso (15 $\mu \mathrm{M})$ produced a long-lasting enhancement of the EPSP that was not blocked by pretreatment with $20 \mu \mathrm{M}$ D-2-amino-5phosphonovalerate (D-APV) alone or D-APV in combination with kynuretic acid (1 mM). The sensitivity of postsynaptic neurons to the glutamate receptor agonist AMPA was unchanged by Iso pretreatment. Superfusion of Iso reversibly blocked the afterhyperpolarization (AHP) that followed a depolarizing current pulse and caused more action potential firing. Intracellular application of a selective inhibitor of the catalytic subunit of cAMP-dependent protein kinase A blocked the effect of Iso on the AHP, whereas Iso-induced potentiation was entirely normal in the same neuron. In addition, Iso decreased the magnitude of paired-pulse facilitation, which is consistent with a presynaptic mode of action.

Substituting the $\mathrm{Mg}^{2+}$ for $\mathrm{Ca}^{2+}$ in the medium completely abolished the Iso-induced enhancement of the EPSP. The effect of Iso also was blocked by low concentrations of (w-agatoxin-IVA, but not by nifedipine or (1)-conotoxin-GVIA. These results suggest that Iso enhances synaptic transmission in the amygdala via a presynaptic site of action: the mechanism underlying the potentiating effect likely is attributable to an increased $\mathrm{Ca}^{2+}$ influx through $\mathrm{P}$ - and/or Q-type $\mathrm{Ca}^{2+}$ channels.

Key words: isoproterenol; glutamate receptor; synaptic transmission; long-term potentiation; calcium channel; amygdala
Norepinephrine (NE) is a putative neurotransmitter that is found throughout the mammalian CNS. The basolateral and central nuclei of the amygdala receive adrenergic innervations from neurons in the locus ceruleus and other brainstem nuclei (Jones and Moore, 1977; Fallon et al., 1978). These catecholaminergic fibers course through the median forebrain bundle and enter the amygdaloid complex primarily through the ventral amygdalofugal pathway.

The role of NE in modulating neuronal activity has been of interest for some time. Previous reports on the hippocampus have shown that NE can produce both excitatory and inhibitory effects on neuronal excitability, depending on the receptor subtypes activated (Mueller et al., 1982; Madison and Nicoll, 1986). Thus, NE increases the single-unit activity and evoked responses via action on $\beta$-adrenergic receptors (Heginbotham and Dunwiddie, 1991). However, activation of $\alpha$-adrenergic receptors caused the attenuation of population spike (Mueller et al., 1982). Intracellular studies with both hippocampal and neocortical slices also showed that postsynaptic $\beta$-adrenergic receptors mediated the reduction of $\mathrm{Ca}^{2+}$ - and $\mathrm{Na}^{+}$-dependent $\mathrm{K}^{+}$currents (Madison and Nicoll, 1982; Foehring et al., 1989). However, no detailed intracellular analysis of $\beta$-adrenergic effect has been performed in the amygdala.

In the present study, we attempted to investigate the effects of isoproterenol (Iso), a $\beta$-adrenergic agonist, on the basolateral amygdala (BLA) neurons. We found that Iso exerts a dual effect on the BLA neurons: (1) Iso enhances cellular excitability by

\footnotetext{
Reccived Sept. 12, 1995; revised Oct. 31. 1995; accepted Nov. 1, 1995.

This work was supported by the National Science Council of Taiwan, Republic of China (NSC-82-(1)42()-B006-(0) 2-M10).

Correspondence should be addressed to Po-Wu Gean at the above address.

Copyright $(1996$ Society for Neuroscience $(1270-6474 / 96 / 161(126-\bullet \$ 05.00 / 0$
}

blocking the spike frequency accommodation; and (2) Iso, via activation of the presynaptic $\beta$-adrenoreceptor, persistently enhances synaptic transmission by increasing transmitter release. Furthermore, by using antagonists selective for L-, N-, P-, or Q-type $\mathrm{Ca}^{2+}$ channels (Miller, 1987; Mintz et al., 1992; Luebke et al., 1993; Takahashi and Momiyama, 1993; Castillo et al., 1994; Wheeler et al, 1994), we first demonstrated that P- and/or Q-channels, but not $\mathrm{L}$ - or $\mathrm{N}$-channels, likely were involved in Iso modulation of transmitter release at rat amygdalar excitatory synapses.

\section{MATERIALS AND METHODS}

Slice preparation and intracellular recordings. Experiments were performed on amygdaloid slices $(500 \mu \mathrm{m}$ thick) prepared from male adult Sprague-Dawley rats $(125-200 \mathrm{gm})$. The rats were decapitated, and transverse slices were cut from tissue block of the brain using Vibroslice (Campden Instruments, Silbey, UK). The slices were placed in a beaker of artificial CSF (ACSF) oxygenated with $95 \% \mathrm{O}_{2} / 5 \% \mathrm{CO}_{2}$ and kept at room temperature for at least $1 \mathrm{hr}$ before recording. ACSF solution had the following composition (in mM): $\mathrm{NaCl} 117, \mathrm{KCl} 4.7, \mathrm{CaCl}_{2} 2.5, \mathrm{MgCl}_{2}$ 1.2, $\mathrm{NaHCO}_{3} 25, \mathrm{NaH}_{2} \mathrm{PO}_{4} 1.2$, and glucose 11 .

A single slice then was transferred to the recording chamber, in which it was held submerged between two nylon nets and maintained at $32 \pm$ $1^{\circ} \mathrm{C}$. The chamber consisted of a circular well of a low volume $(1-2 \mathrm{ml})$ and was perfused constantly at a rate of $2-3 \mathrm{ml} / \mathrm{min}$. A bipolar stimulating electrode (Kopf Instruments SNE-200X, Bern, Germany) was placed in the ventral endopyriform nucleus, near the recording electrode (1-2.5 $\mathrm{mm}$ apart). Orthodromic stimuli were delivered with monophasic constant-voltage pulses at $0.033 \mathrm{~Hz}$ from a Grass stimulator with an isolation unit. Protein kinase A inhibitor (PKI; $45 \mu \mathrm{M} / \mathrm{ml}$; activity, $1 \mu \mathrm{g}$ of protein inhibits 4000 phosphorylating units of protein kinase A; Sigma, St. Louis, MO), dissolved in $3 \mathrm{M} \mathrm{KCl}$, was applied intracellularly by allowing it to leak from the electrode for at least $40 \mathrm{~min}$ according to the method of Cerne et al. (1992).

Intracellular recording microelectrodes were pulled from $1.0 \mathrm{~mm} \mathrm{mi-}$ crofiber capillary tubing on a Brown-Flaming electrode puller (Sutter 
Instruments, San Rafael, CA). The electrodes were filled with $3 \mathrm{M} \mathrm{KCl}$ with resistance ranging from 70 to $120 \mathrm{M} \Omega$. The microelectrode tips were positioned into the basolateral subdivision of the amygdala. Electrical signals were amplified by using an Axoclamp-2A amplifier (Axon Instruments, Foster City, CA) and recorded on a Gould 3200 chart recorder. Signals also were digitized and displayed on a Hewlett-Packard plotter. All data are expressed as mean \pm SE. Statistical analysis was performed using the Student's $t$ test, and $p<0.05$ was considered statistically significant.

Preparation of isolated amygdalar neurons and whole-cell recordings. Amygdalar neurons were isolated using a technique adapted from Kay and Wong (1986). Male Sprague-Dawley rats aged 2-3 weeks were decapitated, and serial transverse slices were cut. Amygdalar regions were dissected under a dissection microscope and then transferred to $10 \mathrm{ml}$ of 1,4-piperazine(ethanesulfonic acid) (PIPES) saline solution in a spinner flask. The temperature was maintained at $32 \pm 1^{\circ} \mathrm{C}$, and $2-3 \mathrm{mg}$ of protease XIV (Sigma) was added. The amygdalar minislices were stirred gently with a magnetic stirrer at a rate sufficient to prevent them from settling, and the solution was bubbled continuously with $95 \% \mathrm{O}_{2} / 5 \%$ $\mathrm{CO}_{2}$. The PIPES saline solution contained (in $\mathrm{mM}$ ): $\mathrm{NaCl} 120, \mathrm{KCl} 5$, $\mathrm{CaCl}_{2} 1, \mathrm{MgCl}_{2}$, glucosc 25, and PIPES 20, pH 7.0.

One hour later, slices were washed with $10 \mathrm{ml}$ of PIPES saline solution ( 3 times), transferred for storage to a holding chamber filled with continuously bubbled PIPES saline solution at room temperature, and kept at least $1 \mathrm{hr}$ before recording. Slices were used within 2-6 hr. When needed, a slice was transferred to the $1 \mathrm{ml}$ of external solution and the neurons were dissociated by trituration using a fire-polished Pasteur pipette with an $\sim 1 \mathrm{~mm}$ tip diameter. The suspension of dissociated amygdalar neurons then was transferred to a $0.5-1 \mathrm{ml}$ recording chamber mounted on an Olympus IMT-2 inverted microscope. Neurons were allowed to settle on poly-L-lysine-coated coverslips.

The whole-cell patch-clamp recording method was used to monitor membrane currents induced by pressure injections ( $10 \mathrm{psi}, 1 \mathrm{sec}$ duration) of AMPA $(100 \mu \mathrm{M})$ in freshly isolated neurons. The pressure pipette was positioned $-50 \mu \mathrm{m}$ from the neuronal soma. Patch pipcttes for whole-cell recording were pulled from borosilicate glass and fire-polished with a resistance of 2-5 M $\Omega$. Pipette solution contained (in mM): K-gluconate 120 , tetraethylammonium chloride 20, HEPES 10 , EGTA 2.25, $\mathrm{CaCl}_{2} 1$, $\mathrm{MgCl}_{2} 2, \mathrm{Mg}-\mathrm{ATP} 4$, and Na-GTP 0.3, $\mathrm{pH}$ 7.3. Whole-cell currents were recorded using a patch-clamp amplifier (EPC-7, List-Electronic, Darmstadt, Germany) and filtered at $10 \mathrm{KHz}$. Tetrodotoxin (300 nM) was added to the external solution to suppress spontaneous activity.

All drugs except nifedipine and 6-cyano-7-nitroquinoxaline-2,3-dione (CNQX) were dissolved in ACSF. Nifedipine and CNQX were dissolved in a dimethylsulfoxide (DMSO) stock solution and kept frozen until the day of experiment. The concentrations of DMSO in the perfusion medium ranged from 0.1 to $0.25 \%$. In all three experiments, DMSO of these concentrations did not affect either the active or the passive properties of neurons. Nifedipine, kyurenate, D-2-amino-5-phosphonovalerate (DAPV), and isoproterenol were obtained from Sigma; $\omega$-conotoxin-GVIA ( $\omega$-CgTX-GVIA), $\omega$-conotoxin-MVIIC ( $\omega$-CgTX-MVIIC), $\omega$-AgatoxinIVA ( $\omega$-Aga-IVA), and CNQX were from Research Biochemicals (Natick, MA).

\section{RESULTS}

Orthodromic stimulation of the ventral endopyriform nucleus evoked an EPSP in BLA neurons. The EPSP is mediated via excitatory amino acids acting predominantly on AMPA receptors (Gean and Chang, 1992). Application of Iso (15 $\mu \mathrm{M})$ persistently potentiated the EPSP amplitude to $198 \pm 10 \%$ of control $(n=8)$. In another six experiments, we pretreated the slices with propranolol $(10 \mu \mathrm{M})$ and found that propranolol blocked the effect of Iso (data not shown). Because NMDA receptors play an important role in $\beta$-adrenergic receptor activation-induced synaptic plasticity in other brain areas (Burgard et al., 1989; Stanton et al., 1989), we examined whether blockade of NMDA receptor prevented the development of Iso-induced potentiation. Figure $1 \mathrm{Al}$ shows that Iso $(15 \mu \mathrm{M})$, administered in the presence of NMDA receptor antagonist D-APV $(20 \mu \mathrm{M})$, increased the amplitude of EPSP to $202 \pm 19 \%$ of control ( $n=13$; Fig. $1 A 3)$, which was not significantly different from that without D-APV preapplication.
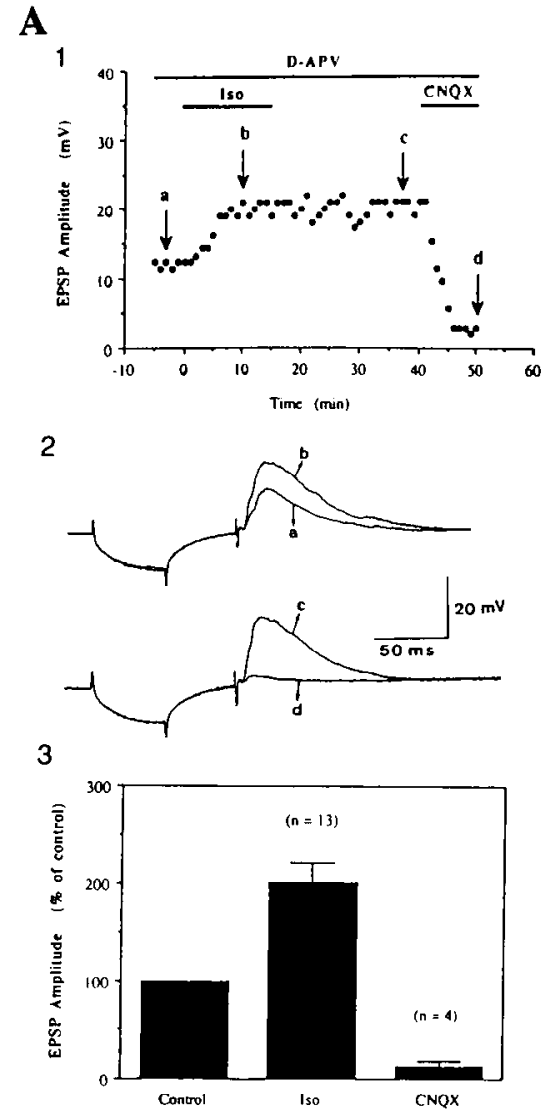

$\mathbf{B}$

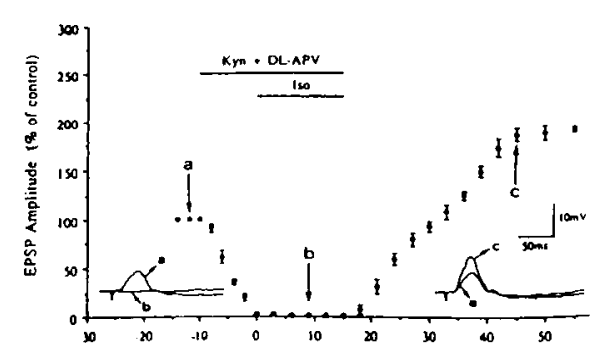

Figure 1. Long-term enhancement of the EPSP by Iso is both NMDAand non-NMDA-receptor-independent. $A l$, The amplitude of the EPSP is plotted as a function of time. Bars denote periods of application of D-APV $(20 \mu \mathrm{M})$, Iso $(15 \mu \mathrm{M})$, and CNQX $(10 \mu \mathrm{M})$. A2, Superimposed records of responses taken at different times indicated in $A 1$. The EPSP was preceded by a transient hyperpolarizing current pulse $(0.15 \mathrm{nA}, 50 \mathrm{msec})$ passed through the recording electrode to monitor the input resistance. A3, Bar graph showing the average increase in the amplitude of EPSP by $15 \mu \mathrm{M}$ Iso $(202 \pm 19 \%$ of control, $p<0.001 ; N-13)$. In four experiments, CNQX $(10 \mu \mathrm{M})$ was applied at the end of experiments to ensure that EPSP was mediated by the AMPA receptors. $B$, Blockade of postsynaptic glutamate receptors with Kyn and DL-APV failed to affect the Iso-induced potentiation. After the evoked responses had stabilized, Kyn (1 mM) and DL-APV $(50 \mu \mathrm{M})$ were added to the bath. Once responses were blocked completely, Iso was applied for $15 \mathrm{~min}$ in the presence of Kyn and DL-APV and the drugs were then washed out. Insets show typical records taken before, during Kyn + DL-APV application, and after Iso in Kyn + Dl-APV and subsequent washout of the antagonists.

The increase persisted long after Iso was washed out. A hyperpolarizing current pulse $(0.1 \mathrm{nA}, 50 \mathrm{msec})$ was passed through the recording electrode to monitor the neuronal input resistance. As depicted in Figure 1 $A 2$, Iso had no measurable effect on either the 
input resistance $(43.3 \pm 2.7 \mathrm{M} \Omega$ before and $43.0 \pm 2.2 \mathrm{M} \Omega$ after the superfusion of Iso, $P>0.1 ; n=10$ ) or the resting membrane potential $(-66.2 \pm 1.1 \mathrm{mV}$ before and $-65.6 \pm 1.1 \mathrm{mV}$ after the application of Iso, $P>0.1 ; n=10$ ).

To address further the question of whether postsynaptic activation of non-NMDA (and NMDA) receptors is required for the effect of Iso, Iso was applied during the blockade of both NMDA and non-NMDA glutamate receptors. Kynuretic acid (Kyn), although having a lower affinity than CNQX, was used to block non-NMDA receptors because it can be washed out quickly. Consistent with previous reports, the EPSP was completely blocked in the Kyn ( $1 \mathrm{~mm})$ - and DL-APV $(50 \mu \mathrm{M})$-containing solution. Iso $(15 \mu \mathrm{M})$ then was added in the presence of glutamate receptor blockers. As shown in Figure $1 B$, after washout of the drugs, a clear potentiation of synaptic transmission occurred. The EPSP amplitude averaged $193 \pm 3 \%(n=5)$ of control $30 \mathrm{~min}$ after washout of Iso.

To determine whether the action of Iso was mediated by pre- or postsynaptic mechanisms, we examined the effect of Iso on the postsynaptic responses to exogenously applied AMPA. The experiments were performed in the presence of tetrodotoxin $(0.5$ $\mu \mathrm{M})$. As illustrated in Figure $2 A$, application of AMPA produced a membrane depolarization $(21.6 \pm 4.8 \mathrm{mV} ; n=8)$. Iso $(15 \mu \mathrm{M})$ pretreatment did not affect the AMPA-induced depolarization $(23.0 \pm 4.5 \mathrm{mV}, P>0.1 ; n=8 ;$ Fig. $2 A 2)$. In addition, Iso $(15 \mu \mathrm{M})$ did not significantly affect currents induced by pressure application of AMPA $(100 \mu \mathrm{M}, 10 \mathrm{psi}$, duration $1 \mathrm{sec} ; 104 \pm 4 \%$ of control; $n=4$ ) in acutely dissociated amygdala neurons measured by whole-cell recording (Fig. $2 B$ ). Furthermore, Iso itself did not induce any change in holding current. These data indicate that the enhancement of EPSP by $\beta$-adrenergic receptor activation is not mediated by a postsynaptic action on the AMPA receptors.

It has been demonstrated repeatedly that the slow $\mathrm{Ca}^{2+}$. activated $\mathrm{K}^{+}$current, $I_{\mathrm{AIIP}}$, underlies the spike frequency accommodation and slow afterhyperpolarization (AHP) in hippocampal and cortical neurons (Madison and Nicoll, 1984; Lancaster and Adams, 1986; Constanti and Sim, 1987). NE acting through $\beta$-receptor, cAMP, and cAMP-dependent protein kinase A (PKA) suppresses the $I_{\text {AlIP }}$ (Madison and Nicoll, 1982, 1986; Pedarzani and Storm, 1993). Therefore, we tested whether Isoinduced potentiation is caused by its inhibition of postsynaptic $I_{\text {AIP }}$ by intracellular application of a specific PKI. The responses of a BLA neuron to a depolarizing current pulse consisted of an initial rapid train of action potentials that slowed or accommodated. The train of action potentials was followed by an AHP. Iso blocked the AHP and, consequently, the spike frequency accommodation was reduced in all cells tested $(n=12$; Fig. $3 A$ ). PKI was applied intracellularly for at least $40 \mathrm{~min}$ before Iso administration. As depicted in Figure $3 B$, the effect on AHP usually seen after Iso either was markedly reduced or was completely abolished, whereas the effect on the EPSP persisted. In six neurons with PKI-filled microelectrodes, the amplitude of EPSP was increased to $200 \pm 5 \%$ by Iso, whereas the AHP was unaffected (AHP of $7.2 \pm 1.1 \mathrm{mV}$ before and $7.2 \pm 1.3 \mathrm{mV}$ after the application of Iso; $n=6$ ). These results suggest that blockade of $I_{\mathrm{AH}}$, in the neuron being recorded is not required for the enhancement of EPSP.

Paired-pulse facilitation (PPF) has been studied extensively and is attributed to an increase in the amount of transmitter released in response to a second stimulus. If Iso-induced potentiation involves presynaptic mechanisms, then it might be associated with a decrease in PPF, because manipulations that enhance transmit-
A

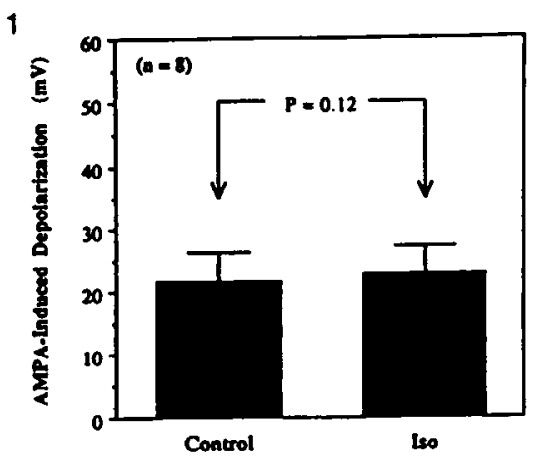

2
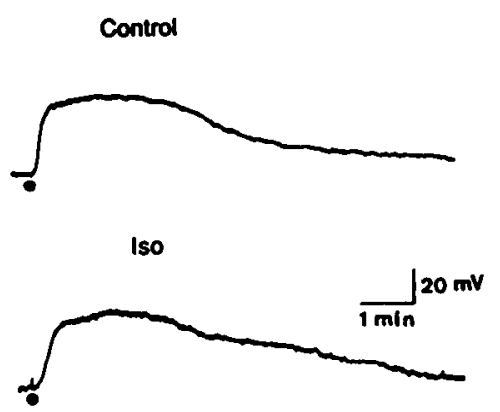

B

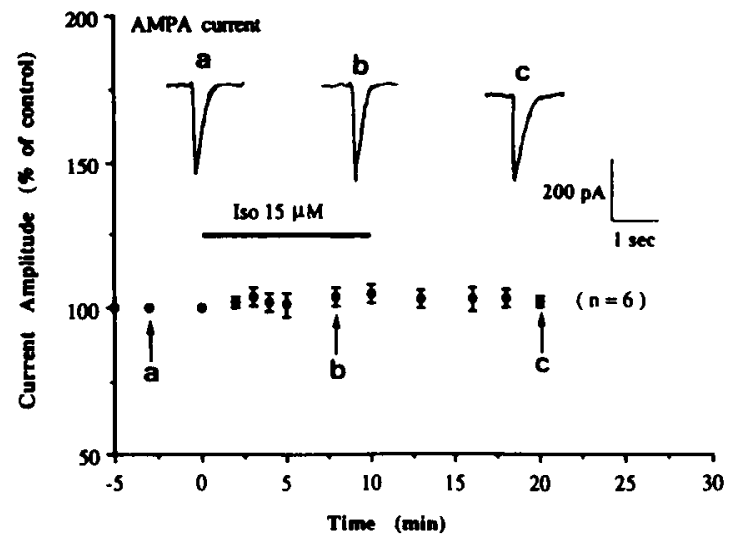

Figure 2. Effect of Iso on AMPA-induced membrane responses. Al, Graphic analysis of the effect of lso pretreatment on the AMPA-induced membrane depolarization. A2, Superfusion of AMPA $(10 \mu \mathrm{M}, 1 \mathrm{~min})$ evoked a membrane depolarization. Pretreatment of the slice with Iso ( 15 $\mu \mathrm{M})$ for 20 min did not affect AMPA-induced depolarization significantly. The experiment was performed in the presence of tetrodotoxin $(0.5 \mu \mathrm{M})$. $B$, Representative traces showing the lack of effect of Iso $(15 \mu \mathrm{M})$ on the amplitude of AMPA (100 $\mu \mathrm{M}, 10 \mathrm{psi}, 1 \mathrm{sec})$-evoked currents. Holding potential, $-60 \mathrm{mV}$.

ter release usually decrease the magnitude of PPF (Manabe et al., 1993; Schulz et al., 1994). Therefore, we compared the magnitude of PPF before and after the treatment with Iso. Synaptic responses to a pair of stimuli were recorded with an interstimulus interval of $60 \mathrm{msec}$ (Fig. $4 A$ ), and PPF is expressed as the percent increase in the second response compared with the first. Figure $4 B$ is a summary of 12 experiments in which initial PPF is plotted on the $x$-axis and the change in PPF induced by Iso is plotted on the $y$-axis. It is clear that in all neurons tested Iso decreased the magnitude of PPF. In addition, there was a significant inverse 
$\mathbf{A}$

1 Control
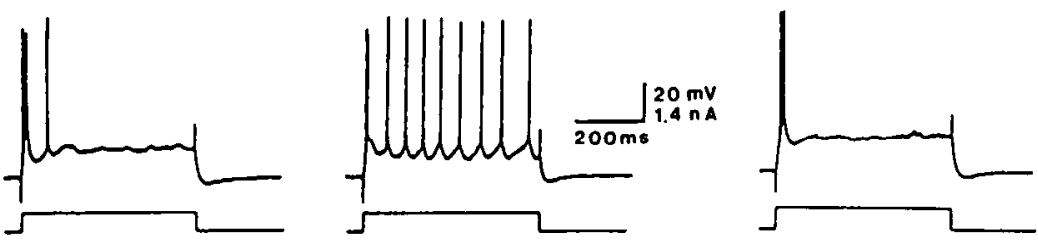

2

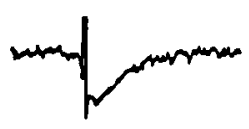

B
Isoproterenol Wash

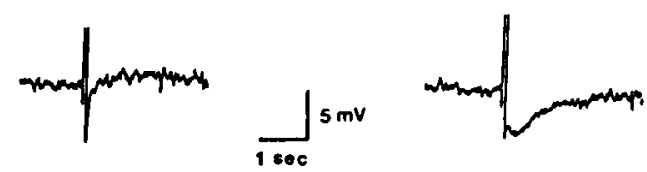

\section{PKI electrode}

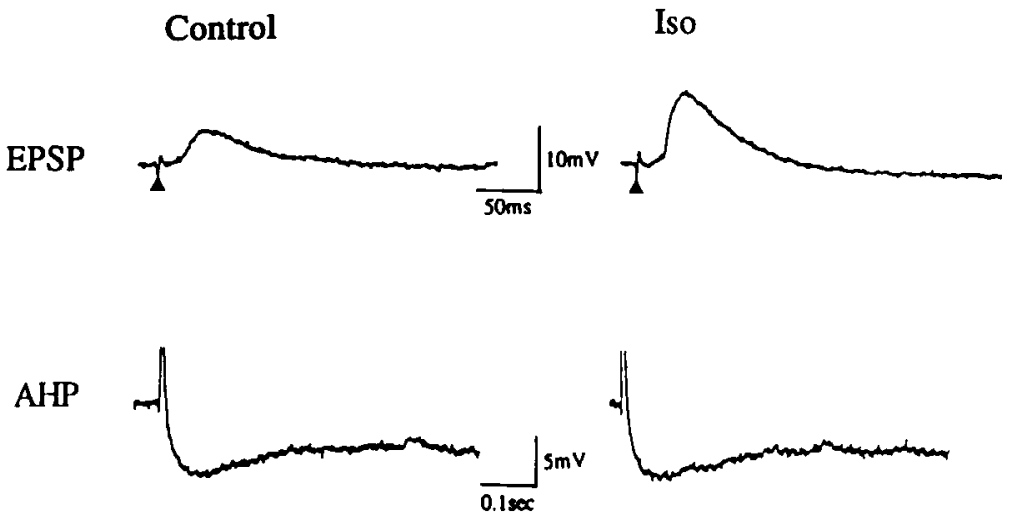

Figure 3. Intracellular application of PKI prevented the effect of Iso on the AHP without blocking the Iso-induced potentiation. $A$, Blockade of the AHP and spike frequency accommodation by Iso. The responses in the middle column were obtained $10 \mathrm{~min}$ after adding $15 \mu \mathrm{M}$ Iso to the bathing solution. The records in Wash were obtained $20 \mathrm{~min}$ after returning to the control solution. $A 1$, Records of the response of a BLA neuron to depolarizing current pulses. The current trace is positioned below the voltage trace. $A 2$, The AHP after the depolarizing pulse. $B$, Representative traces recorded in a neuron impaled with 3 $\mathrm{M} \mathrm{KCl}+\mathrm{PKI}(45 \mu \mathrm{M} / \mathrm{ml})$-filled microelectrodes showing that the lack of effect of Iso on the AHP was not blocked by Iso; in the same cell, however, Iso was effective in potentiating the EPSP.

correlation between the initial PPF and the change in PPF induced by Iso, as demonstrated by the best-fit linear regression line (Fig. $4 B, y=-0.65 x+0.1, r^{2}=0.91 ; n=12$ ). Thus, a larger initial PPF was associated with a greater decrease in PPF, whereas smaller initial PPF was associated with less of a decrease. This result is consistent with a presynaptic mode of action.

Previous hippocampal studies have shown that $\beta$-adrenergic activation potentiated the function of voltage-dependent $\mathrm{Ca}^{2+}$ channels (Fisher and Johnston, 1990), and this increase in channel activity might contribute to enhancement of transmitter release. To investigate the role of presynaptic $\mathrm{Ca}^{2+}$ entry in Iso-induced potentiation, we substituted $\mathrm{Mg}^{2+}$ for $\mathrm{Ca}^{2+}$ in the medium to compensate for the increased $\mathrm{Ca}^{2+}$ influx and then examined the action of Iso under this condition. As shown in Figure 5, the EPSP was completely blocked by $\mathrm{Ca}^{2+}$-free solution and, in each of 11 experiments, application of Iso failed to induce a potentiation. The amplitude of EPSP measured $40 \mathrm{~min}$ after the application of Iso was $102 \pm 2 \%(p>0.1 ; n=11)$. These findings indicate the importance of presynaptic $\mathrm{Ca}^{2+}$ in both transmitter release and Iso-induced potentiation. We have undertaken, therefore, a pharmacological analysis of the effect of selective $\mathrm{Ca}^{2+}$ channel blockers on the Iso-induced potentiation.

Nifedipine $(20 \mu \mathrm{M})$, a selective L-type $\mathrm{Ca}^{2+}$ channel blocker, affected neither the synaptic transmission nor the Iso-induced potentiation. In eight neurons, Iso produced an average of $103 \pm$
$16 \%$ increase in EPSP amplitude in the presence of nifedipine, which was not significantly different from the potentiation induced by Iso alone (Table 1). Application of $\mathrm{N}$-type $\mathrm{Ca}^{2+}$ channel blocker $\omega$-CgTX-GVIA at a saturating dose of $1 \mu \mathrm{M}$ suppressed the evoked EPSP by an average of $83.3 \pm 6.3 \%(\mathrm{p}<0.001 ; n=$ 7; Table 1). The amplitude of EPSP was increased to pretoxin levels by increasing the stimulus intensity, and then Iso $(15 \mu \mathrm{M})$ was applied. Unexpectedly, the amplitude of EPSP was increased to $238 \pm 16 \%$ of control $(n=7)$, which was significantly larger than that observed when slices were treated with Iso alone (Table 1).

$\omega$-Aga-IVA, a peptide purified from the venom of funnel web spider, has been reported to specifically block the P-type $\mathrm{Ca}^{2+}$ channel at very low concentrations (Mintz et al., 1992; Luebke et al., 1993; Randall and Tsien, 1995). $\omega$-Aga-IVA blocks P- and Q-type $\mathrm{Ca}^{2+}$ channels when the concentrations are raised to $\geq 20$ nм (Randall and Tsien, 1995). We have used a series of concentrations in our experiments to define the involvement of P- and $\mathrm{Q}$-type channels in synaptic transmission and Iso-induced potentiation. As shown in Table 1, application of $\omega$-Aga-IVA depressed EPSP amplitude in a concentration-dependent manner. $\omega$-AgaIVA at 1 and $5 \mathrm{nM}$, concentrations that selectively block P-type $\mathrm{Ca}^{2+}$ channels, depressed the EPSP amplitude slightly by $9.8-$ $19.6 \%$. However, raising the concentrations of $\omega$-Aga-IVA to 20-200 nM reduced the EPSP amplitude by $31.3-88.3 \%$. These 
A

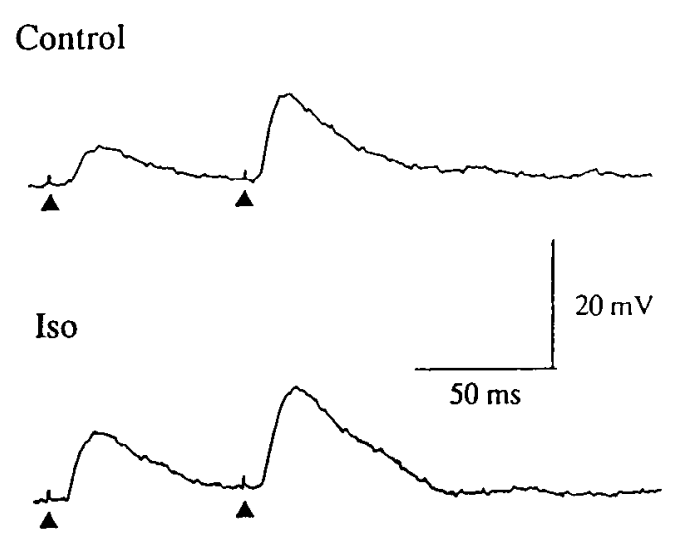

B

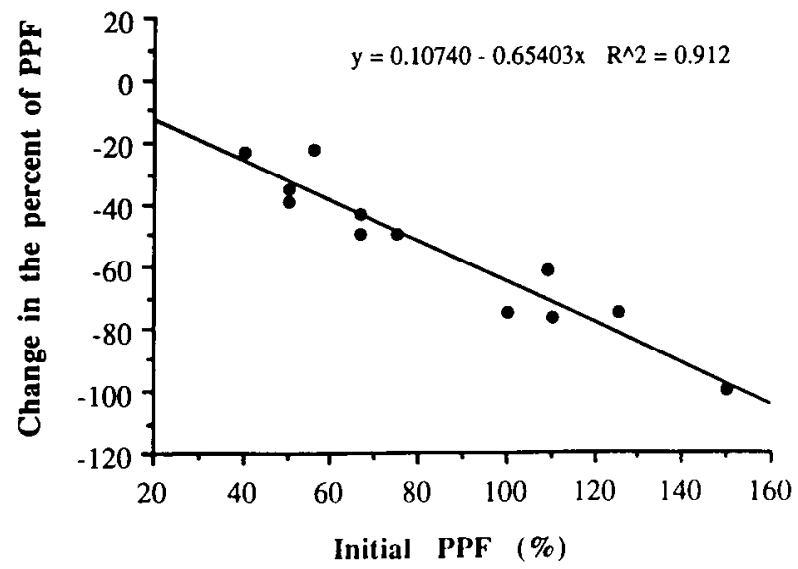

Figure 4. Isoproterenol decreases PPF. $A$, Sample records of EPSPs evoked by paired stimuli ( $60 \mathrm{msec}$ interval) in control condition and after the application of Iso $(15 \mu \mathrm{M}) . B$, The initial PPF was plotted on the $x$-axis, and the change in PPF was plotted on the $y$-axis. The change in PPF was calculated as final PPF minus initial PPF. In all neurons tested, Iso decreased the magnitude of PPF. The best-fit regression line was plotted $(y=-0.65 x+0.1)$, and there was a significant inverse correlation between initial PPF and the change in PPF induced by Iso $(r=0.912)$.

results suggest that $\omega$-Aga-IVA-sensitive $\mathrm{Ca}^{2+}$ channels that participate in synaptic transmission are primarily $\mathrm{Q}$-type, with a small contribution from P-type. More importantly, after 10-15 min of treatment with 5-200 nM $\omega$-Aga-IVA, subsequent Iso application failed to potentiate the EPSP (Fig. 6, Table 1). $\omega$-Aga-IVA at $1 \mathrm{~nm}$ also significantly reduced the magnitude of Iso-induced increase in EPSP amplitude. Iso produced an average of $98.0 \pm 2.9 \%(n=$ 8 ) increase in control, whereas it only caused a $36.2 \pm 3.7 \%(p<$ $0.005, n=4$, unpaired $t$ test) increase in the presence of $\omega$-AgaIVA. The inhibition of EPSP amplitude by $\omega$-Aga-IVA was compared with its effect on Iso-induced potentiation (Table 1). The potency for inhibition of EPSP was approximately two orders of magnitude lower than for the inhibition of Iso-induced potentiation ( IC $_{50}$ values were $\sim 100$ and $1 \mathrm{~nm}$, respectively).

Finally, we tested the effect of a broad-spectrum $\mathrm{Ca}^{2+}$ channel blocker, $\omega$-CgTX-MVIIC, on the Iso-induced potentiation. Application of $1 \mu \mathrm{M} \omega$-CgTX-MVIIC reduced the amplitude of EPSP by an average of $87.3 \pm 2.3 \%(n=6)$. The amplitude of EPSP was restored to its predrug level by increasing the stimulus intensity, and then Iso was applied. As shown in Figure 7, pretreating the slices with $\omega$-CgTX-MVIIC completely abolished the

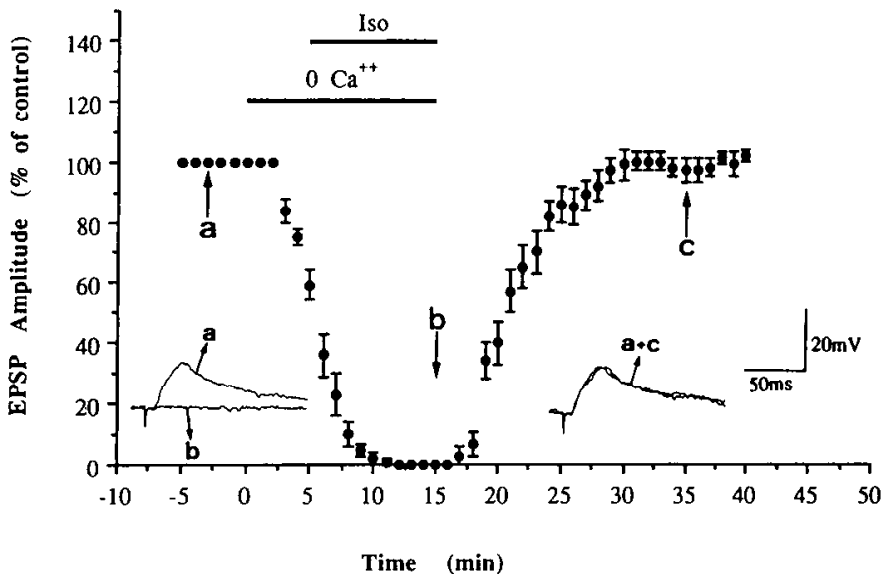

Figure 5. The Iso-induced increase in EPSP amplitude is blocked by $\mathrm{Ca}^{2+}$-free solution. The percent change of EPSP amplitude was plotted against time. Bars denote the periods of delivery of $15 \mu \mathrm{M}$ Iso and $\mathrm{Ca}^{2+}$-free solution. Insets are superimposed traces taken at different times as indicated.

effect of Iso $(99.0 \pm 1.9 \%$ of control; $n=6)$. This result further strengthens the hypothesis that Iso enhances synaptic transmission by increasing presynaptic $\mathrm{Ca}^{2+}$ influx.

\section{DISCUSSION}

\section{Iso-induced synaptic enhancement}

The results of this study provide evidence that Iso enhances synaptic transmission in the amygdala primarily by increasing neurotransmitter release from presynaptic terminals. Three lines of evidence support this conclusion. First, Iso enhances synaptic transmission with negligible changes in resting membrane potential or input resistance of postsynaptic neurons, and the enhancement is accompanied by a decrease in PPF. Second, postsynaptic responses induced by AMPA in the slice preparation and in acutely dissociated cells were not altered by Iso. Third, Isoinduced potentiation is blocked in $\mathrm{Ca}^{2+}$-free medium or by a specific type of $\mathrm{Ca}^{2+}$ channel antagonist, but was unaffected by blockade of postsynaptic non-NMDA and NMDA receptors. These results are consistent with the findings of Chavez-Noriega and Stevens (1994) and Gereau and Conn (1994); they showed that Iso, acting via cAMP cascade, can produce an enhancement of excitatory transmission in area CAl of the rat hippocampus by increasing transmitter release. Furthermore, in the mossy fiber-

Table 1. Effects of $\mathrm{Ca}^{2+}$ channel antagonists on the EPSP amplitude and Iso-induced potentiation

\begin{tabular}{lccc} 
Experiment & $\begin{array}{c}\text { \% Inhibition of } \\
\text { EPSP amplitude }\end{array}$ & $\begin{array}{l}\text { \% Inhibition of } \\
\text { Iso-induced } \\
\text { enhancement }\end{array}$ & $n$ \\
\hline Nifedipine $(20 \mu \mathrm{M})$ & $4.2 \pm 2.9$ & $-5.1 \pm 1.9$ & 8 \\
$\omega$-CgTX-GVIA $(1 \mu \mathrm{M})$ & $83.3 \pm 6.3^{* *}$ & $-40.8 \pm 9.6^{*}$ & 7 \\
$\omega$-Aga-IVA (1 nM) & $9.8 \pm 0.8^{*}$ & $63.1 \pm 1.4^{* *}$ & 4 \\
$\omega$-Aga-IVA (5 nM) & $19.6 \pm 2.4^{*}$ & $95.9 \pm 3.7^{* *}$ & 5 \\
$\omega$-Aga-IVA (20 nM) & $31.3 \pm 2.2^{* *}$ & $96.7 \pm 2.1^{* *}$ & 5 \\
$\omega$-Aga-IVA (100 nM) & $57.6 \pm 1.2^{* *}$ & $97.5 \pm 1.9^{* *}$ & 5 \\
$\omega$-Aga-Iva (200 nM) & $88.3 \pm 4.4^{* *}$ & $98.1 \pm 1.7^{* *}$ & 3 \\
$\omega$-CgTX-MVIIC (1 $\mu \mathrm{M})$ & $87.3 \pm 2.3^{* *}$ & $99.2 \pm 0.6^{* *}$ & 6 \\
& & &
\end{tabular}

Values are means \pm SEM. $n$ is the total of cells tested with each agent under those particular conditions. ${ }^{*} p<0.005$ vs control. ${ }^{* *} p<0.001$ vs control. 
A

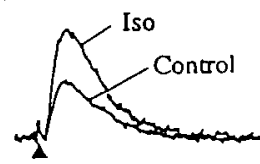

0 Aga
2

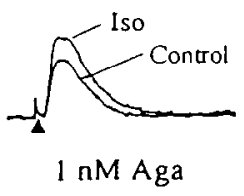

3

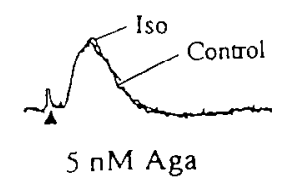

B

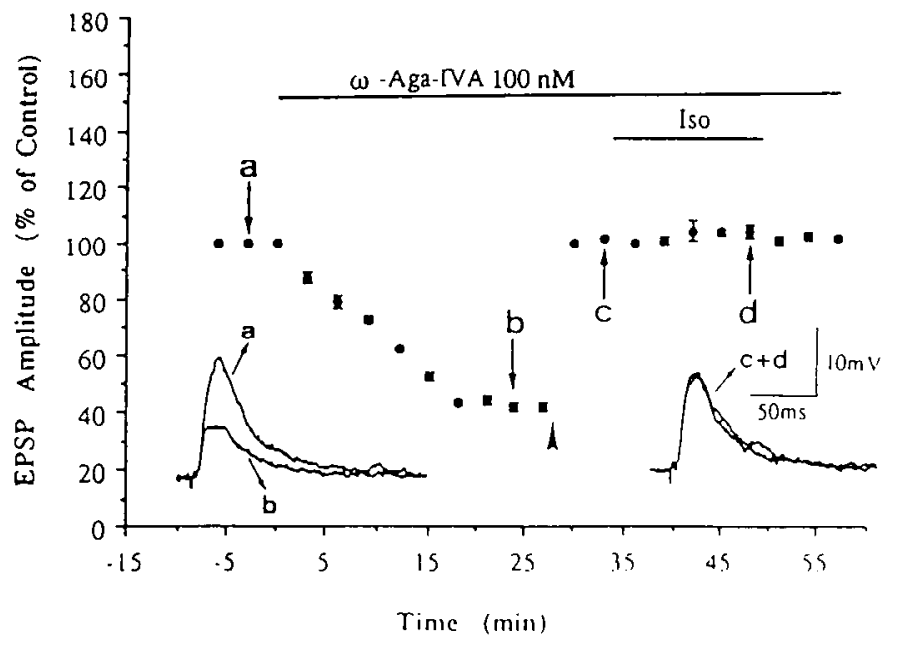

Figure 6. Pretreatment with $\omega$-Aga-IVA blocked the Isoinduced enhancement of synaptic transmission. $A$, Comparison of the effect of Iso in the absence and in the presence of $\omega$-Aga-IVA ( $A g a ; 1$ and $5 \mathrm{~nm}$ ) on the EPSP. In the presence of $\omega$-Aga-IVA, the effect of Iso $(15 \mu \mathrm{M})$ was reduced or completely blocked. $B$, Time course of the effects of $\omega$-Aga-IVA (100 nM) on EPSP and Iso-induced potentiation. $\omega$-Aga-IVA reduced the EPSP amplitude to $-42 \%$ of its baseline. The amplitude of EPSP was restored to its control level by increasing the stimulus intensity (arrowhead), and then Iso $(15 \mu \mathrm{M})$ was applied. Under this condition, Iso did not potentiate the FPSP. Rars denote the delivery of $100 \mathrm{nM} \omega$-Aga-IVA and $15 \mu \mathrm{M}$ Iso.
CA3 pathway, brief applications of a membrane-permeable ana$\log$ of cAMP, Sp-cAMPS, or an adenylyl cyclase activator, forskolin, produce a lasting synaptic potentiation that is induced presynaptically and does not require activation of NMDA receptors (Weisskopf et al., 1993; Huang et al., 1994).

\section{A role for presynaptic $\mathrm{Ca}^{2+}$ entry in Iso-induced potentiation}

We have examined the effect of blocking synaptic transmission, either presynaptically by removing extracellular $\mathrm{Ca}^{2+}$ or postsynaptically by blocking the action of glutamate with glutamate receptor antagonists, on the action of Iso. Iso-induced potentiation was blocked entirely when synaptic transmission was abolished in the $\mathrm{Ca}^{2+}$-free medium. However, blockade of synaptic responses with Kyn and D-APV did not affect the effect of Iso. Because the EPSP was blocked completely in the presence of glutamate receptor antagonists, the membrane potential during application of Iso was well below threshold for activation of high-voltage-activated $\mathrm{Ca}^{2+}$ channels. These results suggest that $\mathrm{Ca}^{2}$ entry into presynaptic terminals, but not into postsynaptic cells via glutamate receptors or voltage-dependent $\mathrm{Ca}^{2+}$ channels, is required for Iso-induced potentiation.

Furthermore, the effect of Iso on the EPSP is unlikely attributable to a direct action on the $\mathrm{Ca}^{2+}$-activated $\mathrm{K}^{+}$currents underlying the AHP because a reduction in the AHP reversed when the Iso was washed out of the bath, whereas the enhancement of EPSP persisted during the entire experimental period. In addition, the inhibition of AHP caused by Iso was markedly retarded after PKI was applied intracellularly; in the same cell, however, the enhancement of EPSP remained intact.

\section{Transmission at excitatory synapses of the amygdala involves $\mathrm{N}-$, , -, and Q-type $\mathrm{Ca}^{2+}$ channels, and the Iso-induced potentiation is blocked selectively by $\mathrm{P}$ - and/or Q-type antagonists}

Neurotransmitter release is initiated by an elevation of intracellular $\mathrm{Ca}^{2+}$ concentration caused by depolarization of the presynaptic nerve terminal and an influx of $\mathrm{Ca}^{2+}$ through voltagedependent $\mathrm{Ca}^{2+}$ channels (VDCCs) (Llinas et al., 1981). We have observed that the stimulus-evoked EPSP was not affected by nifedipine, suggesting that $\mathrm{L}$-type $\mathrm{Ca}^{2+}$ channels normally do not participate in transmitter release (Jones and Heinemann, 1987; Lovinger et al., 1994; Wu and Saggau, 1994). After exposure to 1 $\mu \mathrm{m} \omega$-CgTX-GVIA or $200 \mathrm{~nm} \omega$-Aga-IVA, the EPSP was reduced by 83 and $89 \%$, respectively. This finding suggests that both $\omega$-CgTX-GVIA- and $\omega$-Aga-IVA-sensitive $\mathrm{Ca}^{2+}$ channels support the synaptic transmission in the amygdala. More detailed analysis of the dose dependence of $\omega$-Aga-IVA for inhibition of EPSP revealed that Q-type channels may make up a major portion of the $\omega$-Aga-IVA-sensitive presynaptic VDCCs.

The Iso-induced enhancement of EPSP did not change significantly with nifedipine pretreatment. By contrast, Iso potentiated synaptic transmission to a greater extent in the presence of $\omega$-CgTX-GVIA. A possible explanation is that Iso had no effect on N-channel-mediated transmission, because removal of this component by $\omega$-CgTX-GVIA would leave transmission proportionally more sensitive to Iso. In the presence of low concentrations of $\omega$-Aga-IVA, the potentiating effect of Iso was reduced or diminished. Because the $\mathrm{IC}_{50}$ of $\omega$-Aga-IVA on Iso-induced potentiation matches the high-affinity $K_{\mathrm{d}}$ value ( $\sim 2 \mathrm{Im}$ ) and the $\mathrm{IC}_{50}$ (1-3 nM) for the block of P-type $\mathrm{Ca}^{2+}$ channels in cerebellar 
A

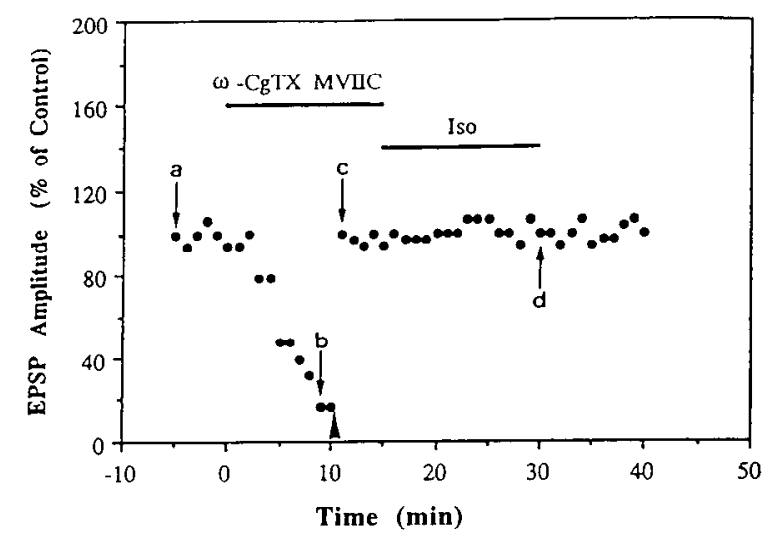

$\mathbf{B}$
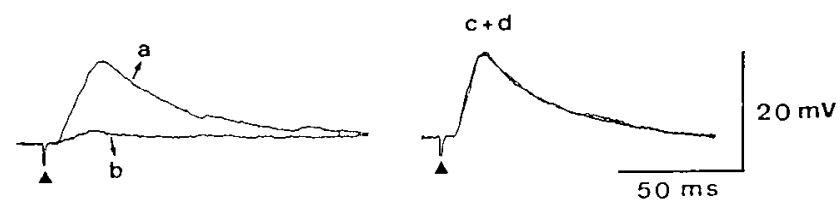

Figure 7. Blockade of the effect of Iso by $\omega$-CgTX-MVIIC. A, Typical experiment showing the effects of $\omega$-CgTX-MVIIC $(1 \mu \mathrm{M})$ on the EPSP and Iso-induced potentiation. In this cell, $\omega$-CgTX-MVIIC reduced the EPSP amplitude to $17 \%$ of its baseline. The amplitude of EPSP was restored to its control level by increasing the stimulus intensity (arrowhead), and then Iso $(15 \mu \mathrm{M})$ was applied. Under this condition, Iso failed to affect the EPSP. $B$, Superimposed traces taken at different times indicated in $A$.

Purkinje neurons and granule cells (Mintz et al., 1992; Randall and Tsien, 1995), it appears that P-type $\mathrm{Ca}^{2+}$ channels are responsible for the action of Iso. However, these results do not necessarily rule out the involvement of Q-current in Iso action, because the distinction between $\mathrm{P}$ - and Q-type channels in the present study was based completely on their differential sensitivities to $\omega$-Aga-IVA, and the $\mathrm{IC}_{50}$ of $\omega$-Aga-IVA for Q-type channels in the amygdala is not known.

\section{Functional implications}

There is general consensus that the amygdala is intimately involved in neuronal plasticity such as epilepsy, learning, and memory (Gloor, 1992; Kesner, 1992; McGaugh et al., 1992). It has been shown that post-training intra-amygdala and peripheral administration of adrenergic agonists enhances the retention of an inhibitory avoidance task. Propranolol, a $\beta$-adrenergic antagonist, not only blocked this memory-enhancing effect (Liang et al., 1986), but it also blocked its own impaired rats' retention of an inhibitory avoidance response (Gallagher et al., 1981). In addition, microinjections of cAMP analogs into the amygdala produced electrographic manifestations of seizures (Gessa et al., 1970). The present study demonstrates that Iso blocks an AIIP, causing more action potential firing. In addition, Iso produces a long-lasting enhancement of F.PSP. These actions may form the cellular basis for the excitatory effects of Iso in the amygdala.

\section{REFERENCES}

Aosaki T, Kasai H (1989) Characterization of two kinds of high-voltageactivated $\mathrm{Ca}$-channel currents in chick sensory neurons. Pflügers Arch $414: 150-156$.
Burgard FC, Decker G, Sarvey IM (1989) NMDA receptor antagonists block norepinephrine-induced long-lasting potentiation and long-term potentiation in rat dentate gyrus. Brain Res 482:351-355.

Castillo PE, Weisskopf MG, Nicoll RA (1994) The role of $\mathrm{Ca}^{2+}$ channels in hippocampal mossy fiber synaptic transmission and long-term potentiation. Neuron 12:261-269.

Cerne R, Jiang M, Randic M (1992) Cyclic adenosine-3',5'monophosphate potentiates excitatory amino acid and synaptic responses of rat dorsal horn neurons. Brain Res 596:111-123.

Chavez-Noriega LE, Stevens CF (1994) Increased transmitter release at cxcitatory synapses produced by direct activation of adenylate cyclase in rat hippocampal slices. J Neurosci 14:310-317.

Constanti A, Sim JA (1987) Calcium-dependent potassium conductance in guinea-pig olfactory cortex neurons in vitro. J Physiol (Lond) 387:173-194.

Fallon JH, Koziell DA, Moore RA (1978) Catecholamine innervation of the basal forebrain. II. Amygdala, suprahinal cortex and entorhinal cortex. J Comp Neurol 180:509-532.

Fisher R, Johnston D (1990) Differential modulation of single voltagegated calcium channels by cholinergic and adrenergic agonists in adult hippocampal neurons. J Neurophysiol 64:1291-1302.

Foehring RC, Schwindt PC, Crill WE (1989) Norepinephrine selectively reduces slow $\mathrm{Ca}^{2+}$ and $\mathrm{Na}^{+}$-mediated $\mathrm{K}^{\prime}$ currents in cat neocortical neurons. J Neurophysiol 61:245-256.

Fox AP, Nowycky MC, Tsien RW (1987) Kinetic and pharmacological properties distinguishing three types of calcium currents in chick sensory neurons. J Physiol 394:149-172.

Gallagher M, Kapp BS, Pascoe JP, Rapp PR (1981) A neuropharmacology of amygdaloid systems which contribute to Icarning and memory. In: The amygdaloid complex (Ben-Ari Y, ed), pp 343-354. Amsterdam: Elsevier.

Gean PW, Chang FC (1992) Pharmacological characterization of excitatory synaptic potentials in rat basolateral amygdaloid neurons. Synapse 11:1-9.

Gereau IV RW, Conn PJ (1994) Presynaptic enhancement of excitatory synaptic transmission by $\beta$-adrenergic receptor activation. J Neurophysiol 72:1438-1442.

Gessa GL, Krishna G, Form J, Tagliamonte A, Brodie BB (1970) Behavioral and vegetative effects produced by dibutyryl cyclic AMP injected into different areas of the brain. $\Lambda \mathrm{dv}$ Biochem Psychopharmacol 3:371-381.

Gloor P (1992) Role of the amygdala in temporal lobe epilepsy. In: The amygdala (Aggleton JP, ed), pp 485-503. New York: Wiley.

Heginbotham LR, Dunwiddie TV (1991) Long-term increases in the evoked population spike in the CAl region of rat hippocampus induced by $\beta$-adrenergic receptor activation. J Neurosci 11:2519-2527.

Huang YY, Li XC, Kandel ER (1994) cAMP contributes to mossy fiber LTP by initiating both a covalently mediated early phase and macromolecular synthesis-dependent late phase. Cell 79:69-79.

Izquierdo I, Da Cunha C, Rosat R, Jerusalinsky D, Ferreira MBC, Medina JH (1992) Neurotransmitter receptors involved in post-training memory processing by the amygdala, medial septum and hippocampus of the rat. Behav Neural Biol 58:16-26.

Jones RSG, Heinemann UH (1987) Differential effects of calcium entry blockers on pre- and postsynaptic influx of calcium in the rat hippocampus in vitro. Brain Res 416:257-266.

Jones BE, Moore RA (1977) Ascending projections of the locus coeruleus in the rat. II. Autoradiographic study. Brain Res 127:23-53.

Kay AR, Wong RKS (1986) Isolation of neurons suitable for patchclamping from adult mammalian central nervous system. J Neurosci Methods 16:227-238.

Kesner RP (1992) I earning and memory in rats with an emphasis on the role of the amygdala. In: The amygdala (Aggleton JP, ed), pp 379-399. New York: Wiley.

Lancaster B, Adams PR (1986) Calcium-dependent current generating the after-hyperpolarization of hippocampal neurons. J Neurophysiol 55:1268-1282.

Liang KC, Juler RG, McGaugh JL (1986) Modulating effects of posttraining epinephrine on memory: involvement of the amygdala noradrenergic system. Brain Res 368:125-133.

Llinas R, Steinberg IZ, Walton K (1981) Presynaptic calcium currents in squid giant synapse. Biophys J 33:289-322.

Lovinger DM, Merritt A, Reyes D (1994) Involvement of $\mathrm{N}$ - and non$\mathrm{N}$-type calcium channels in synaptic transmission at corticostriatal synapses. Neuroscience 62:31-40. 
Luebke JI, Dunlap K, Turner TJ (1993) Multiple calcium channel types control glutamatergic synaptic transmission in the hippocampus. Neuron 11:895-902.

Madison DV, Nicoll RA (1982) Noradrenaline blocks accommodation of pyramidal cell discharge in the hippocampus. Nature 299:636-638.

Madison DV, Nicoll RA (1984) Control of repetitive discharge of rat CA1 pyramidal neurons in vitro. J Physiol 354:319-331.

Madison DV, Nicoll RA (1986) Actions of noradrenaline recorded intracellularly in CA1 pyramidal neurons in vitro. J Physiol (Lond) $372: 221-244$.

Manabe T, Wyllie DJA, Perkel DJ, Nicoll RA (1993) Modulation of synaptic transmission and long-term potentiation: effects on paired pulse facilitation and EPSC variance in the CA1 region of the hippocampus. J Neurophysiol 70:1451-1459.

McGaugh JL, Introini-Collison IB, Cahill L, Kim M, Liang KC (1992) Involvement of the amygdala in neuromodulatory influences on memory storage. In: The amygdala (Aggleton JP, ed), pp 431-451. New York: Wiley.

McGaugh JL, Introini-Collison IB, Nagahara AH (1988) Memoryenhancing effects of posttraining naloxone: involvement of $\beta$-noradrencrgic influcnecs in the amygdaloid complex. Brain Res 446:37-49.

Miller RJ (1987) Multiple calcium channels and neuronal function. Science 235:46-52.

Mintz IM, Venema VJ, Swiderek KM, Lee TD, Bean BP, Adams ME (1992) P-type calcium channels blocked by the spider toxin $\omega$-Aga-IVA. Nature 355:827-829.
Mueller AL, Palmer MR, Hoffer BJ, Dunwiddie TV (1982) Hippocampal noradrenergic responses in vivo and in vitro: characterization of alpha and beta components. Naunyn Schmiedebergs Arch Pharmacol 318:259-266.

Pedarzani P, Storm JF (1993) PKA mediates the effects of monoamine transmitters on the $\mathrm{K}^{+}$current underlying the slow spike frequency adaptation in hippocampal neurons. Neuron 11:1023-1035.

Randall A, Tsien RW (1995) Pharmacological dissection of multiple types of $\mathrm{Ca}^{2+}$ channel currents in rat cerebellar granule neurons. J Neurosci 15:2995-3012.

Schulz PE, Cook EP, Johnston D (1994) Changes in paired-pulse facilitation suggest presynaptic involvement in long-term potentiation. J Neurosci 14:5325-5337.

Stanton PK, Mody I, Heinemann U (1989) A role for $N$-methyl-Daspartate receptors in norepinephrine-induced long-lasting potentiation in the dentate gyrus. Exp Brain Res 77:517-530.

Takahashi T, Momiyama A (1993) Different types of calcium channels mediate central synaptic transmission. Nature 366:156-158.

Wheeler DB, Randall A, Tsien RW (1994) Roles of N-type and Q-type $\mathrm{Ca}^{2+}$ channels in supporting hippocampal synaptic transmission. Science 264:107-111.

Wu LG, Saggau P (1994) Pharmacological identification of two types of presynaptic voltage-dependent calcium channels at CA3-CA1 synapses of the hippocampus. J Neurosci 14:5613-5622.

Weisskopf MG, Zalutsky RA, Nicoll RA (1993) Cyclic-AMP-mediated enhancement and LTP at mossy fiber synapses in the hippocampus. J Neurosci Abstr 19:1708. 